\title{
LUDIC IDENTITIES AND THE MAGIC CIRCLE
}

\author{
Gordon Calleja \\ calleja@itu.dk \\ Center for Computer Games Research, \\ IT-University of Copenhagen \\ Rued Langgaardsvej 7 \\ 2300 Copenhagen \\ Denmark
}

Johan Huizinga's work has received renewed attention with the emergence and growth of Game Studies. An important aspect of Huizinga's explication of play is it's bounded nature. Like other cultural artefacts Huizinga describes in Homo Ludens (1955), the act of gameplaying requires the crossing of a boundary which marks the game from the ordinary world.

The crossing of this boundary into game-space implies a shift in the player's identity that takes them from their everyday, "ordinary" selves, into their ludic selves. Suits (1978) has described this as the "lusory attitude"; a disposition one enters into when interacting with the bounded space of the game.

This chapter examines the concept of the magic circle and considers the ways in which its adoption impacts upon player experience and identity. Following this the chapter considers the work of theorists like Anchor, Ehrmann, Fink and Gombrich which have adopted critical stances towards Huizinga's notion of play as separate from everyday. The inadequacy of the latter becomes more apparent when we consider contemporary efforts to stretch Huizinga's work and apply it to engagement with contemporary digital games. This chapter will thus take to task the taken-for-granted applicability of Huizinga's notion of play for digital games focusing on the challenges this presents to understanding player experience and identity.

\section{An Act Apart}

Huizinga's conception of play as an act apart is most evident in the concept of the magic circle. Initially coined by Huizinga (1955a) in Homo Ludens, the metaphor of the magic circle has been widely adopted by Game Studies theorists (Juul, 2005; Salen \& Zimmerman, 2003) to articulate the spatial, temporal and psychological boundary between games and the real world:

All play moves and has its being within a play-ground marked off beforehand either materially or ideally, deliberately or as a matter of course...The arena, the cardtable, the magic circle, the temple, the stage, the screen, the tennis court, the court of justice, etc., are all in form and function play-grounds, i.e., forbidden spots, isolated hedged round, hallowed within which special rules obtain. All are temporary worlds within the ordinary world, dedicated to the performance of an act apart (Huizinga, 1955a, p. 12).

The compartmentalization of the play-space from the "ordinary world" is a defining element of play, to which Huizinga returns frequently in his work. For Huizinga, play is a "stepping out of real life into a temporary sphere of activity with a disposition all of its own" (Huizinga, 1955 a, p. 9). Additionally, all forms of play, whether engaged in by humans or animals, have some form of rules and it is the adherence to and upholding of these rules that structure and sustain the magic circle (p. 12). 
The space internal to the magic circle is defined by the rules enacted therein, creating "an absolute and peculiar order" (p. 10) within its boundary. The relationship between order and play is necessary for Huizinga's vision of play as the ideal of organized human social structures can he go on to use play as an epiphenomenon upon which other aspects of human society and culture and can be compared and measured. Huizinga's interest in play can be traced to his 1919 book The Waning of the Middle Ages (Huizinga, 1954). In this early work Huizinga argues that despite the unattainable nature of chivalric ideals, chivalry survived long after the socio-cultural contexts that engendered it died because of it's playlike qualities. Later, in The Shadow of Tomorrow (Huizinga \& Huizinga, 1936), Huizinga argues that the crisis in which the world found itself in at the time of writing was symptomatic of a culture which had perverted the ideals of play. So it is no surprise that in his final work we find such a definitive statement about the ordered nature of play:

Here we come across another, very positive, feature of play: it creates order, is order. Into an imperfect world and into the confusion of life it brings a temporary, a limited perfection. Play demands order absolute and supreme (Huizinga, 1955a).

The magic circle thus inscribes the boundary between order and chaos, between the idealized ritual of play and the mess of ordinary life. As Anchor (1978) points out, the notion of a distinct boundary between play and the real world becomes the cornerstone of a model of play against which higher forms of culture are measured. Once the play model is established in the first chapter of Homo Ludens, Huizinga goes on a tour of facets of culture such as: language, law, war, ritual and ritual; discussing how each expresses the play concept.

The separation of play from the everyday that Huizinga proposes has not been without its criticism. Ehrmann (1968) criticizes Huizinga for conceiving of "ordinary life" or "reality" as a stable entity that can be compared, contrasted and measured against play. Huizinga takes for granted the existence of a "reality", perpetually escorted by the hesitant presence of quotation marks, that can, in some non-specified manner, be divorced from culture and/or play. But as Ehrmann rightly argues, there is no reality outside of the culture that constructs it:

The problem of play is therefore not linked to the problem of "reality," itself linked to the problem of culture. It is one and the same problem. In seeking a solution it would be methodologically unsound to proceed as if play were a variation, a commentary on, an interpretation, or a reproduction of reality. To pretend that play is mimesis would suppose the problem solved before it had even been formulated (33-34).

Reality cannot be bracketed by closed or open circles, even if we could argue that a concept such as the latter is logically possible. Reality does not contain play; like any other socioculture construction, play is an intractable manifestation of reality. A consideration of games, whether be it from the perspective of the game as object, game as activity or the game's role in the wider community, is a consideration of reality. As Taylor (2006) has rightly argued, such a perspective ignores the grounded analysis of these objects and activities while sidelining the fact that they are very much part and parcel of the mundane, everyday reality.

As theorists like Anchor (1978), Ehrmann (1968), Fink (1968) and later Copier (2007), Lammes (2006), Malaby (2007), Pargmann and Jakobsson (2006) and Taylor (2006) have argued, a dichotomous view on the relationship between play/games and the real world 
does not survive close analysis, whether this is derived from the critical humanities or the applied social sciences.

\section{The Magic Circle and Player Experience}

The concept of the magic circle has also been applied to the experiential dimension of gameplay. Within game studies it is often taken as a given that game-play involves entering a particular experiential mode that was described by Bernard Suits (1978) as the "lusory attitude" (p. 52). The lusory attitude is closely tied to the notion of the magic circle because it is similarly built on the assumption that players voluntarily step into an attitude which is apart from ordinary life; an experiential mode that occurs only during game playing:

The attitude of the game player must be an element in game playing because there has to be an explanation of that curious state of affairs wherein one adopts rules which require one to employ worse rather than better means to reach an end ( $p$. $52)$.

Although Suits was not (understandably) considering digital games in his writing, the adoption of his theory by contemporary researchers such as Salen and Zimmerman (2004) requires some attention. The voluntary decision to follow an inefficient course of action in order to play by the rules only applies to the socially negotiated aspect of digital games yet the majority of actions possible in digital games are programmed into the game system and cannot be changed. One cannot decide to ignore the rules written into a game like Fable II (Lionhead Studios, 2008) and, for example, drag a chair found in one's house to the town square and decide to sit there. The game does not allow for this to take place because the actions are not programmed into it. Similarly the player cannot jump off a low ledge onto the ground instead of running around the prescribed path simply because it would be more efficient because this particular game does not allow that. More efficient ways of doing things outside of the rule structure imposed by the game are simply not available to the players.

Perhaps a more serious problem with Suits' notion of the lusory attitude is that it is formulated as a defining element of games. This creates a problematically circular argument that essentially claims games are activities that require a lusory attitude and that the lusory attitude is an experience that occurs when playing a game. If we had to follow Suits' logic, the inability in a number of digital games, particularly single-player ones, to voluntarily adopt inefficient means in playing them means that we cannot enter into a lusory attitude, and thus such activities are not games.

It is illogical to claim that play refers simultaneously to a mode of human experience and a form of activity. As Malaby (2007) argued this makes a problematically deterministic claim which views every engagement with a game engenders a specific experiential mode (the lusory attitude, for example) determined by the very act of engaging with the game.

Opposition to the magic circle as a form of experiential bracketing has been particularly strong from researchers conducting qualitative studies with players. Ethnographic work by Taylor (2006), Malaby (2007), Copier (2007), and Pargman and Jakobsson (2006) indicates that such a separation is not found in the situated study of gamers:

Problems with using the concept of the magic circle as an analytical tool have made themselves known now and again. These problems become especially clear when the researcher in question has actual empirical material at hand that he or she 
without much success tries to understand by applying the dominant paradigm of the separateness of play (Pargman \& Jakobsson, 2006, p. 18).

An attempt to create a clean demarcation between the game-experience and the experience of the world (supposedly) external to it will be severely challenged to explain how the players' personal and social histories can be excluded from the game activity. It is hardly possible for the game-space to block out the complexity of social and personal relations. The lived experience of the players invariably informs, to different degrees depending on circumstance, the experience of the game and vice-versa.

There is a severe challenge to any form of discreet bracketing of an aspect of experience that expresses a specific mind-set entered into during game-play. This is particularly evident in digital games since the upholding of game-rules is, for the most part, performed by the machine code. It would be incredibly mis-leading to label all forms of interactions in virtual environments with ludic properties as having a specific experiential disposition by the very virtue of engagement therein. We are better served by furthering our understanding of game engagement un-burdened by such normative assumptions.

\section{The Second Boundary: Virtual as Unreal}

If the magic circle formulates all games as separate due to their ludic nature, digital games encounter a second boundary of separation from the "real" of everyday life: the virtuality attached to their digital nature. This is not a division suffered by digital games only but all digital media ranging from the Internet to any form of virtual environment. These have been characterised from their earliest days by their separation from the real world. Barlow and Kapor (1990) were two of the earliest writers to adopt the rhetoric of the frontier to describe the Internet:

Over the last 50 years, the people of the developed world have begun to cross into a landscape unlike any which humanity has experienced before. It is a region without physical shape or form. It exists, like a standing wave, in the vast web of our electronic communication systems. It consists of electron states, microwaves, magnetic fields, light pulses and thought itself...

In its present condition, Cyberspace is a frontier region, populated by the few hardy technologists who can tolerate the austerity of its savage computer interfaces, incompatible communications protocols, proprietary barricades, cultural and legal ambiguities, and general lack of useful maps or metaphors.

The frontier metaphor, taken directly and uncritically from cyberpunk fiction, fostered the idea that virtual worlds lie on the other side of a geographical boundary that separates them from the real world on the other side of the screen. The image of the "hardy technologists" venturing into an austere and savage "landscape" clearly appealed to the imagination fuelled by Gibson's Neuromancer, published in 1984 . There is an uncanny resemblance between the register used here and that used by Gibson in his fiction. The fictional image of cyberspace presented in Neuromancer became a fact looming on the foreseeable technological horizon. The frontier rhetoric did not stop at Barlow and Kapor. It became a common trope of writers describing new technologies like Rushkoff (1994), Rheingold (1993), Mitchell (1995) and others in the nineties. The comparison with the frontier also appealed to the early days of settlement of America, the excitement inflamed by the potential dangers of this newly discovered wild landscape:

The early days of cyberspace were like those of the western frontier. Parallel, breakneck development of the Internet and of consumer computing devices and 
software quickly created an astonishing new condition; a vast, hitherto-unimagined territory began to open up for exploration (p. 109).

The rhetoric of the frontier is problematic because it creates the notion of a boundary between the real and the virtual rather than seeing the latter as a constituent of the former. Fundamental concepts like the relationship between the real and the virtual underpin any discussion of digital media and it is thus crucial to consider carefully the assumptions they entail.

The "virtual" in digital games is most significantly characterised by the vast landscape of potential configurations of text and its actualisation. This potential emerges from the persistent interaction of human subjectivities with each other and the textual world written for their habitation, and, in the case of online game-worlds, is constantly being re-inscribed by the readings and practices of its inhabitants. This constant process of actualizing real human relations - love, hate, frustration, competition and collaboration - is accelerated by what Bolter and Grusin (1999) have called the "hypermediacy" of networked access.

The computer does not constitute the virtual in itself. It is a necessary tool for enabling the manifestation of the actual-virtual dialectic. The applications that run the digital games, MMOGs, hypertexts and other digital artefacts are fully realised in their coded structure. The clusters of programmed code interact in a predetermined way until the point of contact with the interpreting human subjectivity. It is at this juncture that the virtual comes into force:

Potential, not virtual, for the digital engram and the software used to read the text predetermine a set of possibles, which, though immense, are numerically finite and logically bound. However, it is not quantity that distinguishes the possible from the virtual. The essential distinction is to be found elsewhere. If we consider the mechanical substrate alone (hardware and software), computer technology provides only a combination of possibles, albeit infinite, and never a problematic domain. Digital storage is a potentialization, display a realization... The virtual begins to flourish with the appearance of human subjectivity in the loop, once the indeterminateness of meaning and the propensity of the text to signify come into play, a tension that actualization or interpretation, will resolve during the act of reading (Lévy, 1998, pp. 52-53).

It is the interaction of the player with the complex problematic presented by the game rules, environmental mechanics, representational signs and the hardware interface that engenders a movement from virtualization to actualization and back again. Virtual environments, as defined above, are unique sites of mediated instantiation of this recursive process of actualization and virtualization. The process moves from the creation of a problem, and thus virtualization, in the design of the text to be traversed, to the creation of a solution: the actualizing of the text through interpretation of the surface signs. The possibility for exerting agency within the environment beckons the question "what shall I do next?", creating another problematic; a re-virtualization that requires the solution of practice. The player actualizes thought into action, in itself a creation of a further problematic: the inscription of one's actions onto the environment, affecting the clusters of coded data as well as other users in the environment. The complexity of this recursive process is multiplied by the presence of others and emphasized by the immediacy enabled by networked computing. 
Digital games are designed to enable the actualization of desired experience. Stating that this is their principal attractor would ignore the heterogeneity of players and games, but I would be confident in claiming that it is, at least a key factor that makes them such compelling media. This view of the virtual gives a constructive account of the essential features of virtual environments and worlds.

The utility of the concept of the virtual applied to digital games and other forms of virtual environments lies in emphasizing their creative potential for actualizing a theoretically infinite range of possible experiences. The ontological value of these experiences are very much of the order of the real, not its opposite.

\section{Crossing the Double Boundary}

The prevalence of these two boundaries, the ludic and the virtual, has created a tendency of viewing engagement with digital games as a crossing into a realm of the virtual-ludic other. This sense of transportation is the foundation upon which metaphors that describe intense forms of engagement with digital games are built. One such metaphor is immersion:

Immersion is a metaphorical term derived from the physical experience of being submerged in water. We seek the same feeling from a psychologically immersive experience that we do from a plunge in the ocean or swimming pool: the sensation of being surrounded by a completely other reality, as different as water is from air, that takes over all of our attention, our whole perceptual apparatus (Murray, 1998, p. 98).

Virtual environments are an important part of our everyday reality and should be seen as deeply interwoven with our sense of the real. A metaphor of virtual world habitation, therefore, should draw upon the experiential gestalts of everyday habitation; that is, a view of consciousness as an internally generated construct based on the organization of external stimuli according to existing experiential gestalts (Damasio, 2000; Dennett, 1991; Lakoff \& Johnson, 2003).

The metaphors of immersion founded as it is on an exclusionary logic, does not enable such a perspective on the phenomenon. I have therefore argued elsewhere (Calleja, 2007b, 2011) that this metaphor be replaced with that of incorporation. Incorporation accounts for the sense of virtual environment habitation on two, simultaneous, levels: in this first sense of the metaphor, the virtual environment is incorporated into the player's mind as part of their immediate surroundings, within which they can navigate and interact. In the second sense, the player is incorporated (in the sense of embodiment) in a single, systemically upheld location in the virtual environment at any single point in time.

Incorporation thus operates on a double axis: the player incorporates, in the sense of internalizing or assimilating, the game environment into consciousness while simultaneously being incorporated through the avatar within that environment. The simultaneous occurrence of these two processes is a necessary condition for the experience of incorporation. Put in another way, incorporation occurs when the game world is present to the player while simultaneously the player is present, via their avatar, to the virtual environment.

\section{Identity and incorporation}

Issues of identity in virtual environments, and consequently digital games, have been discussed primarily from the perspective of the opportunities for the formation, experimentation and expression of identity (Turkle, 1995, 2005; Castronova, 2005; Filiciak, 
2003; Rheingold, 1993). These discussions importantly highlight the role that games play in re-writing identity through digital game-play (Hand and Moore, 2006; Turkle, 1995, 2005). The focus here is on the presentation of self to others in a virtual environment. This addresses one aspect of the incorporation being described here; the presence to others made possible by avatarial embodiment. This topic has received much attention, and it would be redundant to revisit such a discussion in the limited space of this paper. What we will discuss instead is the second, complementary, half of the incorporation equation; the influence of absorbing to consciousness a game-world and its inhabitants on the player's identity.

When a player experiences incorporation, the game environment is absorbed into consciousness as a place inhabited. The significance of this for a contemporary notion of a digitally-mediated identity can only be understood fully if we acknowledge how powerful these experiences of habitation can be. Players have an increasingly varied plethora of simulated experiences within settings of their choosing available to them. Inhabiting virtual environments can have lasting effects on the players' sense of self, by expanding the realm of possible interactions into increasingly more appealing "shared fantasies" (Fine, 1983) instantiated through simulation. One of the research participants describes a sequence that aptly conveys incorporation and the lasting effect it can have on the player:

There was a time when I was playing through Guild Wars... it was in the war-torn parts of Ascalon. I was working through some ruins and I turned this corner, and came across this massive, ruined cathedral with this gorgeous stained glass window that was mostly intact. I just stopped, and stared at it. I worked my way around it as much as I could to see it from all angles and ended up on a rise a little above it, just watching it. I don't remember the time of day, but it might have been like a sunset and I swore I could practically feel the breeze on my face and hear the wildlife. If I could pay to experience that in real life I would. And I would pay a lot. It was a real moment for me, a real experience that I carry with me. (Rheric, World of Warcraft)

This account brings to the fore the intensity of emotion felt in such holistic incorporating experiences. If we were to remove the fantasy names from the Rheric's account it would not be obvious to the reader that he was describing an experience in a virtual world. Rheric relates the event with strong connotations of inhabiting a place, emphasized by the synaesthesiac addition of stimuli that were not part of the environment ("I could practically feel the breeze on my face and hear the wildlife"). Rheric's concluding sentence emphasizes the experiential significance of this event and the lack of separation between it and a nonmediated equivalent and most importantly, the effect this has on Rheric's lived experience.

Rheric's identity is not only effected by the role he plays through the construction of his ingame character, or the relationships he forms with the community on his Guild Wars (NC Soft, 2006) server, but also by the experiences that are incorporated into consciousness, as much as any other significant moment in the physical world. Identity is not effected because of the otherness of the virtual environment, as is too often taken for granted, but because of the internalisation of the world as an engaging, and often memorably exciting, place to inhabit.

\section{Ludic-Identity?}

In light of the above it seems challenging to talk about a ludic-identity. Once the magic circle, or any such defined boundary between the game and everyday is destabilized, so is the notion of an identity that is specific to game-play. What I am arguing here is not that it is not possible to discuss a particular identity that comes to the fore in some (but certainly 
not all) engagements with games, but that this form of identity is (a) not specific to games (b) does not occur in every engagement.

Following from the logic of incorporation discussed above and explicated elsewhere (Calleja 2007b, 2011), we come to a more robust understanding of in-game identities by focusing instead on the dimensions of involvement the specific game or genre of games affords (Calleja, 2007a, 2007b, 2011). This avoids the normative assumptions carried by play as both a marker of experience and form of activity. That is, by taking the specific form of involvement afforded by the game in question we do not make the normative claim that every engagement with a game creates a specific form of experience and hence a specific form of (ludic) identity. Focusing on the concrete forms of involvement also avoids the ambiguity of the term (Sutton-Smith, 1997) which often lumps together a variety of disparate experiential phenomena without acknowledging the composite nature of the term in question. This creates a problematic situation where the experiences being contained in one formulation of play in a certain context can be completely different from the experiences contained by another, essentially talking about completely different experiences and dressing them as equivalent.

The argument I am making here does not reject the fact that there is an element of boundary negotiation and interpretation in our engagement with games, but that the notion of games as acts apart, somehow separate from the real or everyday, is not the best formulation of this or any other experiential boundary. More complex models of boundary negotiation and interpretation have been formulated in other fields that would more adequately account for the phenomenon in question. Sebastian Deterding (Deterding, 2009), for example, makes a convincing argument for using Goffman's (Goffman, 1986) Frame Analysis to express the boundary negotiation that occurs in game engagements instead of the magic circle. The metaphor or model we use to understand the nature of game engagement forms a foundation upon other, more specific discussions on our interaction with games. Such foundational concepts need careful consideration and the clearest and analytically richest of formulations; qualities which the magic circle, as a foundational concept, does not possess.

Anchor, R. (1978). History and Play: Johan Huizinga and His Critics. History and Theory, 17(1), 63-93.

Barlow, J. P., \& Kapor, M. (1990). Across the Electronic Frontier. Retrieved 5th February, 2008, from http://w2.eff.org/Misc/Publications/John Perry Barlow/?f=across the ef.article.txt

Blizzard Entertainment. (2004). World of Warcraft. PC: Vivendi Universal.

Bolter, J. D., \& Grusin, R. (1999). Remediation : understanding new media. Cambridge, Mass.: MIT Press.

Calleja, G. (2007a). Digital Game Involvement. Games and Culture(2), 236-260.

Calleja, G. (2007b). Digital Games as Designed Experience: Reframing the Concept of Immersion. Unpublished Doctoral Thesis, Victoria University of Wellington, Wellington.

Calleja, G. (2011). In-Game: From Immersion to Incorporation. Cambridge, Mass.: MIT Press.

Copier, M. (2007). Beyond The Magic Circle: A Network Perspective On Role-Play In Online Games. Unpublished Doctoral, Utrecht University. 
Damasio, A. R. (2000). The feeling of what happens : body, emotion and the making of consciousness (New ed.). London: Vintage.

Dennett, D. C. (1991). Consciousness explained. Boston: Little Brown and Co.

Deterding, S. (2009). The Game Frame: Systemizing a Goffman Approach to Video Game Theory. Paper presented at the DIGRA 2009: Breaking New Ground: Innovation in Games, Play, Practice and Theory.

Dibbell, J. (2006). Play Money: Or, How I Quit My Day Job and Made Millions Trading Virtual Loot. New York: Basic.

Ehrmann, J. (1968). Homo Ludens Revisited. Yale French Studies(41), 31-57.

Fink, E. (1968). The Oasis of Happiness: Toward an Ontology of Play. Yale French Studies(41), 19-30.

Goffman, E. (1986). Frame analysis : an essay on the organization of experience (Northeastern Univ. Press ed.). Boston: Northeastern Univ. Press.

Huizinga, J. (1954). The waning of the Middle Ages; a study of the forms of life, thought, and art in France and the Netherlands in the XIVth and XVth centuries. Garden City, N.Y.,.

Huizinga, J. (1955a). Homo ludens; a study of the play-element in culture (1st Beacon paperback ed.). Boston: Beacon Press.

Huizinga, J. (1955b). Homo ludens; a study of the play-element in culture. Boston,: Beacon Press.

Huizinga, J., \& Huizinga, J. H. (1936). In the shadow of tomorrow. New York,: W. W. Norton \& Company.

Juul, J. (2005). Half-real : video games between real rules and fictional worlds. Cambridge, Mass.: MIT Press.

Lakoff, G., \& Johnson, M. (2003). Metaphors we live by. Chicago: Univ. of Chicago Press.

Lammes, S. (2006). Spatial Regimes of the Digital Playground. Paper presented at the Gaming Realities: A Challenge for Digital Culture, Athens.

Lévy, P. (1998). Becoming virtual : reality in the digital age. New York: Plenum.

Linden Lab. (2003). Second Life. PC: Linden Lab.

Lionhead Studios. (2008). Fable II. Xbox 360: Microsoft Game Studios.

Malaby, T. (2007). Beyond Play: A New Approach to Games. Games and Culture, 2(2), 95113.

MindArk. (2003). Project Entropia. PC: MindArk.

Mitchell, W. J. (1995). City of bits : space, place, and the infobahn. Cambridge, Mass.: MIT Press.

Murray, J. H. (1998). Hamlet on the holodeck : the future of narrative in cyberspace. Cambridge, Mass.: MIT Press.

Origin Systems. (1997). Ultima Online. PC: Electronic Arts.

Pargman, D., \& Jakobsson, P. (2006). The Magic is Gone: A Critical Analysis of the Gaming Situation. Paper presented at the Gaming Realities: A Challenge for Digital Culture, Athens.

Rheingold, H. (1993). The virtual community : homesteading on the electronic frontier. Reading, Mass.: Addison-Wesley.

Rushkoff, D. (1994). Cyberia : life in the trenches of hyperspace. London: Flamingo.

Salen, K., \& Zimmerman, E. (2003). Rules of play : game design fundamentals. Cambridge, Mass.: MIT Press.

Suits, B. H. (1978). The grasshopper : games, life, and Utopia. Toronto ; Buffalo: University of Toronto Press.

Sutton-Smith, B. (1997). The ambiguity of play. Cambridge, Mass.: Harvard University Press.

Taylor, T. L. (2006). Play between worlds : exploring online game culture. Cambridge, Mass. ; London: MIT Press.

Yee, N. (2006). The Labour of Fun. Games and Culture, 1(1), 68-71. 
